\title{
Graduate Student-Athletes: An Examination of Identity Roles and Transition
}

\author{
Amanda Blakewood Pascale ${ }^{1}$, Elizabeth Gregg ${ }^{1}$, \\ and Andrea Buenano ${ }^{2}$ \\ ${ }^{1}$ University of North Florida, ${ }^{2}$ University of Cincinnati
}

\begin{abstract}
Graduate student-athletes are increasing in numbers on college and university campuses, though much of the research on student-athletes focuses on undergraduate student populations. This study examines how graduate student-athletes balance their identities as both a student-athlete and as a graduate student. Analysis of the data revealed three major themes: (a) life revolves around sport, (b) graduate student-athlete role conflicts, and (c) preparation for life after sport. Findings suggest that the graduate student-athlete participants in this study used their status as graduate students as a part of a strategy for transition, whereby they began to adopt new roles and routines in preparation for their lives after sport. Implications for practice and policy to support graduate student-athletes are discussed.
\end{abstract}

Keywords: student-athlete, identity, graduate student, transition

College athletes often encounter challenges when balancing their athlete and student identities (Foster \& Huml, 2017; Yopyk \& Prentice, 2005). Much of the literature on athletic identity focuses on undergraduate student populations; however, in an increasingly common practice, student-athletes who earn an undergraduate degree are electing to use their remaining athletic eligibility while pursuing a graduate degree. A 2015 survey of Division I athletic programs determined that about 2\% of student-athletes were graduate students (National Collegiate Athletic Association, 2015). The proportion of graduate student-athletes is greater in revenue-producing sports where strong athletic identity is most prevalent. According to Haslerig (2017), in 2014 approximately $4 \%$ of men's basketball and football players were enrolled in post-baccalaureate programs, and football players represented about $36 \%$ of graduate student-athletes. The total number of graduate student-athletes nearly doubled from 2007 to 2014 (Haslerig, 2017).

The increased numbers of graduate student-athletes can be attributed in part to the introduction of the 2006 National Collegiate Athletic Association (NCAA) graduate transfer rule that allows student-athletes with remaining eligibility to either pursue a graduate degree at their undergraduate institution, or transfer and play immediately at another school (Haslerig, 2017; Martin, 2008). Other changes such as increased academic support, due in part to the adoption of the NCAA Academic 
Progress Rate (APR) policy in 2003 (National Collegiate Athletic Association, n.d.), have also increased the numbers of graduate student-athletes. The trend suggests that numbers of graduate student-athletes will continue to increase. However, little is known about the graduate student-athlete experience, and it stands to reason that graduate student-athletes may face more challenges related to balancing their student and athlete identities than their undergraduate counterparts.

In order for universities to better serve this unique population, more research is needed. The purpose of this study is to examine how graduate student-athletes balance their identities as graduate student and intercollegiate athlete. In this context, we explore how student-athletes arrive at the decision to pursue graduate study, challenges they face when the role demands of their dual identities conflict, and strategies they use to manage their expectations of themselves as athletes and graduate students.

\section{Background and Literature}

Each year in the United States, over 460,000 students participate in intercollegiate sports (Lu, Heinze, \& Soderstrom, 2018). Because of the often intense time demands of athletics, their dual roles in college are often in direct conflict (Adler \& Adler, 1987; Lu et al., 2018; Settles, Sellers, \& Damas, 2002; Wendling, Kellison, \& Sagas, 2018). The intercollegiate athletic experience requires the student-athlete to participate in at least 20 hours of athletic-related activities per week, whereas their studies often require that much time or more.

Athletic self-identity has been defined as "the degree to which an individual thinks and feels like an athlete" (Gustafsson, Martinent, Isoard-Gautheur, Hassmén, \& Guillet-Descas, 2018, p. 56). According to Marcia (1993), in order for a person to develop their overall identity, they must explore potential roles and related behaviors, which then lead to a personal decision about a chosen identity. Thereafter, an individual develops a belief system, investment in the development of skills, and a commitment to a given occupation or sport. Because intercollegiate athletic participation requires a great deal of time, some student-athletes are restricted in exploring identities outside of sport. A typology of student-athletes has been developed that consists of four main groups, including scholar-athletes who are committed to both athletic and academic roles, pure athletes, pure scholars, and those who do not demonstrate commitment to either (Snyder, 1985).

\section{Athletic Identity and Academic Experience}

Athletic identity has a strong impact on the ability of a student-athlete to thrive in the classroom. Either the student identity or the athletic identity can take precedence for a given student-athlete ( $\mathrm{Lu}$ et al., 2018). Those with higher levels of athletic identity may select less rigorous majors, engage less with course material, and experience less academic success than those with higher levels of academic identity. Student-athletes feel most like students when they are engaged in academic tutoring 
or spending time at academic centers for athletes, and most like athletes when on the field or while wearing athletic gear on campus (Lu et al., 2018). Over the course of a student-athlete's career, the athletic portion of their dual role takes on more importance than the student role (Adler \& Adler, 1987).

Athletes on a men's basketball team that competed in a major conference, and who had high levels of athletic identity, selected majors that they perceived to be more conducive to their team obligations (Adler \& Adler, 1987). Because student-athletes must juggle their athletic and academic obligations, many experience role conflict. Additionally, the label "dumb jocks" adds to their role conflict and self-perceptions of their ability to succeed (Adler \& Adler, 1987). NCAA academic eligibility requirements require a full-time course load of at least 12 hours per semester and good academic standing in order to compete, so the student and athlete roles are interdependent (Wendling et al., 2018). To resolve role conflict, some athletes, especially those in revenue-producing sports, reduce or even abandon their academic role (Adler \& Adler, 1987).

Despite the clear pressures of the dual role, many student-athletes have positive academic experiences. Previous literature has demonstrated that student-athletes have higher graduation rates, higher levels of academic adjustment, better health outcomes, higher levels of adherence to authority, greater levels of character development, enhanced self-esteem and confidence, and enhanced institutional attachment compared to their non-athlete peers (Melendez, 2006). Other benefits of athletic participation include decreased feelings of loneliness and stress among first-year students (Chen, Snyder, \& Magner, 2010; Miller \& Kerr, 2003). Previous research indicated that participation in amateur sport could lead to higher levels of attendance in graduate school and overall lifetime earnings (Coakley, 1983).

Other studies have highlighted the negative impacts of intercollegiate athletic participation on student-athletes. Problems such as lack of social interaction with non-team members, substance abuse, depression, violent behavior, and disordered eating have been found to plague some college athletes (Bacon \& Russell, 2004; Brewer, Van Raalte, \& Linder, 1993; Chen et al., 2010; Fields, Collins, \& Comstock, 2007; Jolly, 2008; Miller \& Kerr, 2003; Yukhymenko-Lescroart, 2018). Some scholars have determined that student-athletes have a more difficult time succeeding in the classroom than their non-athlete peers. For example, student-athletes were viewed by their peers as less intelligent and less capable of succeeding in college than non-athletes (Sailes, 1993). Some studies have shown that student-athletes in revenue sports in particular struggle in the classroom. Men who compete in revenue-producing sports such as football and basketball are outperformed by non-athletes in the classroom (Pascarella, Truckenmiller, Nora, Terenzini, Edison, \& Hagedorn, 1999).

Women have been found to have higher levels of student identity salience than men (Harrison et al., 2009; Sturm, Feltz, \& Gilson, 2011). Women overall, and men who compete in non-revenue sports, were statistically similar to non-athletes in terms of academic performance. Overall, women who compete on top athletic teams perform significantly better academically than men at the same level of athletic per- 
formance (Bailey \& Bhattacharyya, 2017). Further, student-athletes who compete at elite levels and who are successful academically share various traits that enable them to flourish in both roles. For example, female student-athletes had higher self-esteem and transformational leadership characteristics than their non-athlete peers (Galante \& Ward, 2017). It is plausible that student-athletes who possess both elite athletic prowess and the innate characteristics that allow them to succeed in the classroom end up as graduate student-athletes (Bailey \& Bhattacharyya, 2017).

Students whose identities center on athletics are more likely to seek degrees that are less demanding and more conducive to high levels of focus on athletic obligations. This phenomenon is typically described in the literature as clustering, in which a large percentage (typically greater than $25 \%$ ) of student-athletes on one team major in a particular subject at a given institution (Fountain \& Finley, 2011; Haslerig \& Navarro, 2016; Schneider, Ross, \& Fisher, 2010). Academic clustering leads to limited career options for athletes, particularly those in revenue-producing sports. To combat potential negative outcomes associated with academic clustering, Haslerig and Navarro (2016) recommended that athletes receive strong support for career planning and career development in their undergraduate years, especially as they consider further education after college. That said, other studies (Chen et al., 2010; Lally \& Kerr, 2005; Miller \& Kerr, 2003) found that during the latter years of college, student-athletes' focus shifts more towards their academic identity.

\section{Athletic Identity and Athletic Retirement}

While in general the literature suggests that participation in collegiate athletics leads to positive outcomes, athletes with strong levels of athletic identity were less academically successful than those with lower levels (Hale \& Waalkes, 1994). Strong athletic identity is also associated with lower levels of career maturity and burnout (Hale \& Waalkes, 1994; Foster \& Huml, 2017). A strong student-athlete identity can be problematic as graduation approaches, as can the daunting prospect of transitioning away from athletic identity. Student-athletes reported the retirement process to be difficult when they did not have well-developed options for life after sport (Mihovilovic, 1968). To combat negative outcomes associated with high levels of athletic identity, it has been suggested that the college adjustment experience for student-athletes include the development of a balanced academic and personal identity in addition to athletic pursuits (Melendez, 2006).

Because athletic participation requires a great deal of time, role conflict between being a student and an athlete is often present (Adler \& Adler, 1991). Those with a strong athletic identity are more likely to experience negative ramifications during college (Foster \& Huml, 2017). This effect was most pronounced among student-athletes who believed athletic performance was the only portion of their identity that mattered. Emotional and psychological difficulties are often experienced by retiring athletes, leading to depression, anxiety, substance abuse, decreased self-confidence, and in some instances, eating disorders (Blinde \& Stratta, 1992; Ogilvie \& Howe, 1982; Sinclair \& Orlick, 1993; Svoboda \& Vanek, 1982). Athletes have been reported to lose their sense of self upon retirement (Lally, 2007), and this phenomenon is 
particularly problematic for athletes with high levels of athletic identity (Adler \& Adler, 1987). Those athletes who deemphasize their athletic identity and place additional importance on their academic identity and future career have an easier time with the retirement transition (Lally, 2007).

The literature on graduate student-athlete identity is sparse. However, two notable pieces relate to the current study. Participants in a study of 11 graduate student-athletes who competed in Division I football made conscious efforts to distance themselves from negative stereotypes such as the "dumb jock" label (Haslerig, 2017) study. Participants stated that graduate courses provided them with the opportunity to prove to their peers that they were capable of thriving intellectually at the graduate level. Other graduate student-athletes discussed initially being unaware of the opportunity to pursue graduate education with their remaining eligibility. Haslerig recommended a concerted effort to inform all undergraduate student-athletes of the possibility of enrolling in graduate school, in order to both overcome the information barrier and to shift the culture of teams toward academic achievement. Other recommendations included changing the language used to describe graduate student-athletes away from the "fifth-year athlete" label, and to increase dialogue among coaches, academic success professionals, and players regarding graduate student-athletes' successes in the classroom.

Once athletes become graduate students, they explore academic pursuits more freely than in their undergraduate years (Haslerig \& Navarro, 2016; this finding conflicts with participant data in the current study, as some indicated that they selected a graduate program based on its perceived fit with their athletic obligations). The participants in their study reported that they had to work hard to overcome barriers created by their academic commitments so they would have time to pursue non-athletic interests and social activities. These graduate student-athletes reported that they chose their graduate program because it fit with their career interests, they were intellectually curious about the topic, or a combination of the two. The same students felt well-equipped to assist their undergraduate student-athlete peers and capable of navigating academic support systems. The authors determined that graduate student-athletes had high levels of self-efficacy. One implication of their study was that in order for the population of graduate student-athletes to grow, information must be shared with undergraduate student-athletes.

Despite these scholarly contributions, more research on graduate student-athlete identity is necessary in order to truly understand the unique population. Understanding the process of identity balance will enable the creation of policies and practices that support student-athletes in their transition from undergraduate to graduate student and later away from sport and school. The current study is such a contribution.

\section{Theoretical Perspectives}

To frame our study, we turned to the perspectives provided by role strain theory (Goode, 1960) and adult transition theory (Schlossberg, Waters, \& Goodman, 1995). Role strain theory asserts that social institutions depend on role relationships, that in- 
dividual identity consists of multiple roles, and that an individual's cumulative roles almost always exceed their ability to meet them all satisfactorily. Thus individuals prioritize various role demands over others, a phenomenon referred to as role strain (Goode, 1960). The prioritization of role demands can become difficult when the various role demands conflict with one another or compete for time and resources. Consider, for example, a graduate student-athlete who is required to travel to an away tournament during the semester when classes are held. When these situations occur, Goode suggested that individuals employ coping strategies, some of which may be dysfunctional, to justify their prioritization of role demands.

The process of transition has been described by identifying the ways in which individuals cope or adjust to change (Schlossberg et al., 1995). The four factors that influence the success of the transition process (termed the $4 \mathrm{~S}$ system) are the external context (situation) and the individual (self) together with the resources available to them (support) and the effectiveness of the individual's utilization of the supports provided (strategies). The ideas posited by Goode (1960) in role strain theory and Schlossberg et al. (1995) in adult transition theory helped the authors make meaning of the data in the generation of themes, and also provided perspective in the interpretation of these themes and discussion.

\section{Methodology}

This study is a multisite (two universities) case study, bounded by time and by participant criteria described below (Flyvbjerg, 2011; Merriam, 2009). We explored the identity-balancing process of student-athletes from a subjectivist lens. That is, we wished to give voice to the experiences and reality of our participants (Patton, 2002).

\section{Participants and Site Selection}

All participants met the pre-determined criteria of being Division I scholarship student-athletes enrolled in their first year of a graduate level degree. Two participants (Grady and Kenzie) attended University A, a pseudonym for a public 4-year, Division I institution located in the southeastern United States. The remaining four participants attended University B, a pseudonym for a public 4-year, Division I institution located in the midwestern United States. Table 1 includes demographic information for all participants.

Participant recruitment occurred in several ways. First, administrators from selected athletic conferences were asked for lists, with contact information, of participants who fit the criteria. Those students were contacted via email to determine their interest and availability in participating in the study. Second, athletic directors at selected universities were contacted and asked to share information regarding the study with student-athletes who met the criteria. Finally, potential participants were solicited via a national conference presentation where preliminary findings from initial participants were shared. These strategies resulted in a total pool of six graduate student-athletes from two different institutions who agreed to participate in the study. These six student-athletes represented a variety of sports, both revenue and non-revenue, and were diverse in race and gender. 


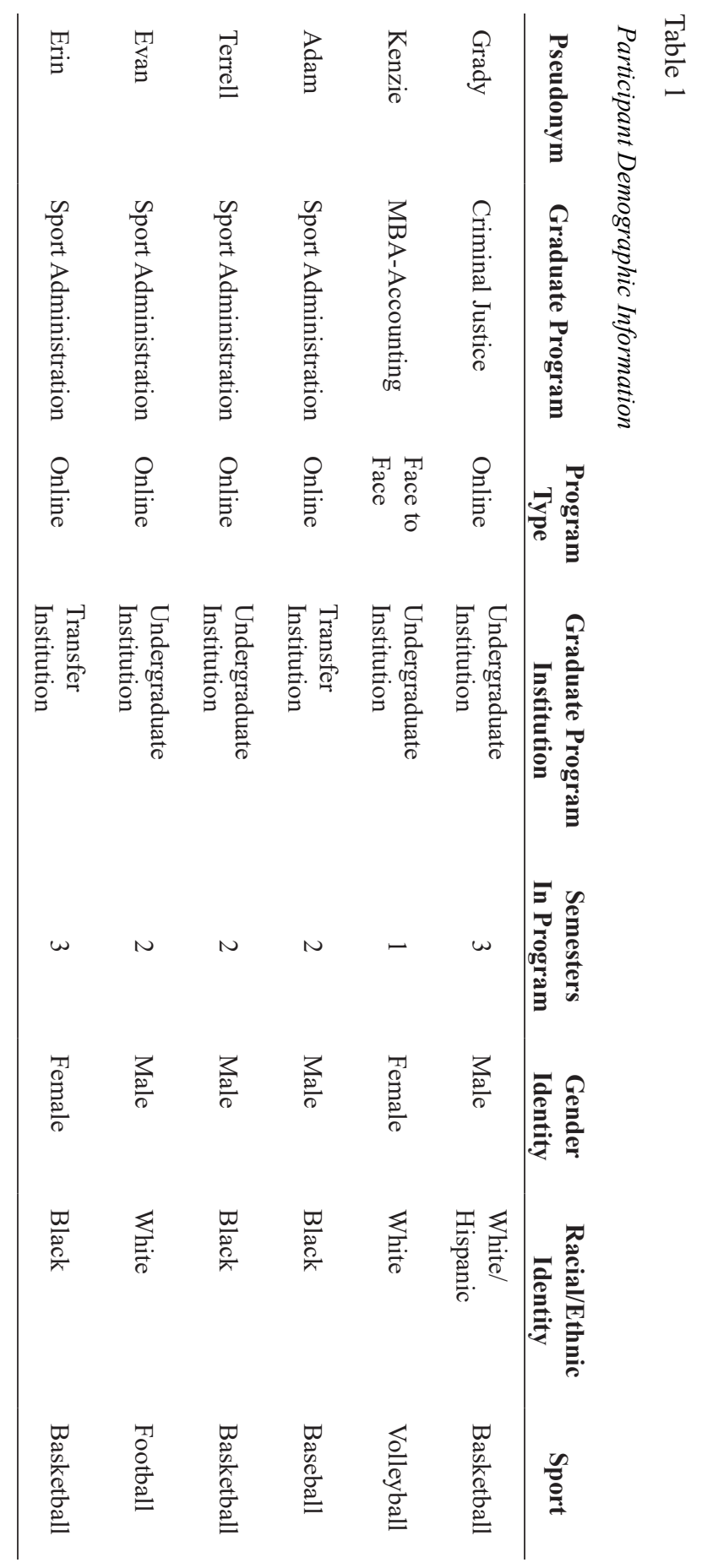




\section{Data Collection}

Given the intent of this study to understand the perspectives of the participants, rich descriptive interviews were deemed the most appropriate way to collect data (Patton, 2002). The students took part in in-person, one-on-one, semi-structured, in-depth interviews. Interviews were conducted during the spring and summer of 2019. With participant consent, all interviews were recorded and transcribed by a researcher-trained graduate assistant. Relevant documents, including policies regarding student-athletes, graduate student program descriptions, and curricula were obtained for analysis.

\section{Data Analysis}

Data analysis took place in two phases. In phase one, researchers conducted interviews with two participants and obtained relevant documents at University A. After these interviews were recorded and transcribed, researchers carried out the constant comparison method of analysis (Glaser \& Strauss, 1967). First transcripts were read and re-read to generate initial, or open, codes. This process produced over 400 open codes. For instance, two examples of open codes were "sport all life" and "always knew wanted to play". At the completion of this process, associations between codes were identified, a process known as axial coding. During the axial phase open codes were reduced to an average of 26 associated concepts or ideas. To take the example of the open codes identified previously, "sport all life" and "always knew wanted to play" were linked together as related concepts because of the mention of sport always being a part of the students' lives. When differences of opinion in data interpretation emerged, the researchers met to resolve those differences. Finally, after three rounds, the axial codes and concepts were collapsed into overarching themes. The aforementioned open and axial codes eventually became a part of the first theme "life revolves around sport". Once formed, the themes were cross-referenced with documents, including student-athlete academic policies and graduate study program and curriculum descriptions, to generate a more complete understanding of the student-athletes' experiences within the context of their institution. The themes that emerged from the data were examined through the lenses of the theoretical perspectives guiding this study. That is, as findings emerged we considered the data in the context of the ideas posited by Goode (1960) in role strain theory and Schlossberg et al. (1995) in adult transition theory. These ideas helped us generate themes and provided perspective for the interpretation of these themes and discussion.

Phase two of the analysis took place two months after phase one. Once new data from University B were collected and interviews transcribed, the researchers continued the constant comparison method of analysis, where the new data were considered and compared with existing themes to confirm and corroborate the findings.

\section{Trustworthiness and Credibility}

Several measures were taken to enhance trustworthiness and credibility of the findings and interpretation. We used several of the eight validation strategies for qualitative research recommended by Creswell and Poth (2018). First, our two-step data 
analysis approach allowed the time and space for peer review. Preliminary findings were presented at a national conference, and conference session attendees provided feedback and initial thoughts on the themes and interpretations. Second, our one-onone semi-structured interviews generated rich, thick descriptions of participant experiences. Finally, we triangulated both the researchers and the data. Three researchers were involved in the analysis process. Researchers one and three conducted interviews, and researchers one and two carried out the coding process. This approach allowed for an internal check in which one researcher was involved in both interviews and coding, one was involved in only coding, and the third did not code but verified the coding was consistent with their interpretation from the interview process. The two researchers involved in the coding process individually reviewed transcripts and then came together to discuss interpretation of codes and themes and resolve any differences. Use of multiple sources of data including institutional policies, program descriptions, and curricula as well as interview data provided additional opportunity for triangulation. For example, several participants mentioned how travel as an athlete affected their graduate student responsibilities. As we interpreted our findings, we consulted institutional policies on student-athlete related travel and academics to contextualize the students' reported experiences.

\section{Findings}

Analysis of the data revealed three major themes: (a) life revolves around sport, (b) graduate student-athlete role conflicts, and (c) preparation for life after sport. These themes are explored in more detail here.

\section{Life Revolves Around Sport}

For these graduate student-athletes, sport was the center of their lives. All six participants shared that they had always known they had wanted to play their sport, and thus sought opportunities and schools that would allow them to pursue their passion while also earning their degree. As Grady explained in his opening sentence, "[I] always knew I wanted to play basketball." Similarly, Kenzie opened her interview by sharing "I always knew I wanted to play Division I." When asked to describe their typical day, all participants detailed highly regimented schedules that revolved around their sport. These days included activities such as weights, practice, rehabilitation, stretching, talking with coaches, eating to fuel their bodies for performance, or in some cases, hanging out with teammates at the gym or using the locker room facilities to get ready for their day. Several students shared that they used space around the athletic facilities for studying. As Erin explained:

I'll go up to my coach's office and there's a room, the conference meeting room. I'm sitting in the conference meeting room for three hours and just . . . I have to be away from my home, so I'm not laying in my bed . . . being away from everything and it's quiet. 
These examples point to the importance of the role of the athlete and illustrate how athletic identity manifests in these student-athletes' lives.

However, the athlete role differentiates these students from typical graduate students. Reminiscent of the phenomenon of academic clustering (Fountain \& Finley, 2011; Haslerig \& Navarro, 2016; Schneider et al., 2010), several of our participants indicated that their graduate program was not their original choice for study, but was selected because they felt it would be more compatible with their athletic demands. For instance, Adam originally planned to pursue a Masters of Business Administration (MBA) but decided against doing so: "I'm probably glad that I didn't [pursue an MBA] just with baseball cause I felt like it would have been a lot. . . I think it would have been too rigorous and too difficult to deal with baseball season starting now." Grady originally wanted to pursue a master's degree in Social Work, but decided against it because of the internship requirements "I was thinking Social Work actually first ... that's what I was going to try to do first, but with the internships that you had to do, it wasn't really possible while I was playing . . . and so obviously I couldn't." Grady eventually selected a master's degree in Criminal Justice, as he felt the online nature of the program would allow him the flexibility he needed. Half of our participants noted they had originally planned to pursue a different degree, but ultimately decided on a program they deemed compatible with the demands of their sport.

Of our six participants, five were enrolled in online programs. For some, athletic advisors encouraged them to pursue their degree online, while others, like Grady, individually concluded that online offerings would best accommodate their busy schedules. While online programs brought flexibility, some of our participants expressed that they found the online format to be challenging, and they felt they might have selected a face-to-face format if not simultaneously pursuing sport. For example, Adam cited the online format of his classes as his biggest challenge:

The online aspect is probably the biggest challenge, because I love to ask questions and I love to get clarity on things ... it's not as timely so if I have a question or a concern . . . you kind of have to send an email and then wait until the instructor emails you back.

These additional examples indicate the importance of the role of "athlete" for these students. Not only day to day decisions and schedules, but also major life decisions such as which graduate program to pursue, were based on the expectations and demands of their sport. Of our participants, half noted they had originally planned to pursue a different degree, but ultimately decided on a program they deemed compatible with the demands of their sport. While some of the time our participants were able to accommodate both athletic and scholarly demands, there were some instances where these two roles came into conflict and created strain, the second theme of this study. 


\section{Graduate Student-Athlete Role Conflicts}

Our participants reflected on several aspects of graduate study that they felt were in conflict with the expectations of their athletic demands. For instance, several participants noted that they were assigned more group projects in graduate school than they were during their undergraduate programs, and that group work could be challenging particularly when they were expected to work together with classmates during their athletic season when they were also traveling. Kenzie explained:

There are group presentations in my managerial accounting class and there's basically three days you can present and I was going to be gone on two of those days ... so I had to tell my group, 'like I can really only present on the middle day' ... but it's just tough in master's classes, there's so much group work ... . and you may have a group that doesn't understand ... and [part of your grade] is based on peer evaluations.

Adam, who was in an online program, corroborated Kenzie's identification of group work as a challenge as a graduate student-athlete: "We have a couple of group projects and it's kind of difficult to work in a group." Evan also talked about the increased number of group projects in his graduate program as compared to his undergraduate work. When asked about the major differences between undergraduate and graduate study he replied: "There's just more to pay attention to ... just like the projects and things. I'm in like four group projects right now and that never really happened in undergrad."

Group work was only one aspect of graduate school that participants noted as a challenge to balancing their roles as graduate students and athletes. Traveling was commonly mentioned as one of the biggest sources of role conflict. Many of the participants talked about being proactive as a strategy to balance competing demands of sport and school, but that at times the conflict was unavoidable. Grady described this process as learning how to "edit your life" as he shared a story about being behind in his graduate work while traveling for basketball:

One time we were on a long road trip, and it was a week where we had a lot of reading, a lot of reading, and I actually wasn't able to get it all done, and then we were traveling the next week ... we were in Mexico for a tournament . . and so it was a couple weeks in a row where it all kind of piled on me and I didn't have a lot of time to catch up because we were so busy with basketball and in that moment instead of getting so worried about grad school ... I had to put that aside and be like ok, I'm at a tournament right now and there's nothing I can do about that right now ... if I'm overstressing about school then I'm not gonna do what I need to do for the basketball team.

Grady expanded on this point by saying, "[Being a graduate athlete] is obviously harder than undergrad ... with how hectic the season can get ... like this week we had three games and seven days we were traveling ... with missing classes ... I 
was scared about that." Kenzie also mentioned travel as the hardest part of balancing sport and graduate study, particularly because of the way her graduate classes were scheduled. As is typical of many graduate programs that are intended to accommodate working professionals, her classes met in the evenings, with less frequent meetings and longer class meetings than undergraduate offerings. Kenzie expressed that when she missed class because of travel it was difficult for her to catch up on the material. Moreover, many of her classes were seminar style in nature, and could not be replicated or "caught up":

The hardest parts were travel . . travel weekends or travel days . . . um like on Thursdays. . . . We're risking a lot of Thursday classes . . . that's usually when you miss because that's when you travel for the weekends ... I missed 12 Thursday classes this fall . . miss 12 classes and that's like your whole semester . . . that's really tough.

Several participants also spoke about how the standards for success in graduate school as compared to undergraduate study added to their pressure as a graduate student-athlete. For the participants in this study, to remain in good standing as a graduate student required no less than a "B" average, and grades below a "B" could jeopardize their status in the program. In contrast, in their undergraduate programs grades of "C" were acceptable. Evan confirmed this point:

I was gonna mention that, the grade . . . you can't get below a B right . . . and then you have one B minus I think . . . that's definitely . . . it puts more pressure ... I like it because it's honestly made me more attentive to making sure that I'm not just passing through . . . like I actually know what I'm doing . . . not just like getting through it because you can get through it with a $\mathrm{C}$ like a lot of people would do that.

Erin also indicated that as a graduate student she felt she was held to higher standards than her undergraduate teammates and was expected to set an example for them: "It's a different standard that [my coach] will hold me to, and she's just like I'm teaching you differently." She expanded on this point by sharing that her status as a graduate student-athlete led her to feel accountable in the example she set for her teammates:

You're held to a different standard in the master's program ... I don't wanna, me as a person, a leader and one of the older people on the team, I don't want to be called out at all in a huddle because I have a $\mathrm{C}$ in this class and I'm not supposed to ... that's a new challenge for me, accountability.

While at times she indicated she was resentful of the amount of work she put into setting a good example through success in her graduate program, she also noted that she embraced her new leadership role because she recognized her personal transformation: 
It's funny because my team looks to me as a mom, and I've never been that ... it was just that transition, from being like the team clown to being the team mom instead ... I've kind of grown into the role they've given me.

Erin's recognition of her personal transformation through her adoption of new roles with corresponding role demands foreshadowed her process of preparation for her life after sport, the third theme of this study.

\section{Life after Sport}

Each of our participants detailed, in their own way, how they intended to prepare for life after sport. Several participants directly discussed that pursuing a graduate degree played a large part in their transition. Terrell explained that when he was a freshman, he was hesitant to take on too much academic responsibility so he could "have fun" in college, but changed his perspective to "take advantage" of the opportunity to earn a master's degree while still playing basketball.

Coming from high school, I'm like man, I'm in college, [I am gonna]have fun . . . but as I got here, got wise - I guess older, I realized what I really have in front of me ... I'm like yeah [I am gonna] take advantage of it, [I am gonna] do it, [I am gonna] get it ... when I'm done playing sports...I still wanna be around sports.

Terrell was not the only participant whose views on graduate study shifted. Several other participants expressed that they originally pursued graduate study only to continue playing their sport, but that as they progressed through their program they began to view it as an opportunity to transition out of sport into the "real world". Kenzie shared: "I still have eligibility left in volleyball, but I finished my undergraduate program ... I have to take classes to play volleyball." Despite her admission of pursuing her degree to allow her to continue her sport, when asked if she would continue her degree if her eligibility were to end, she said she would finish and that she credited her graduate program with helping her to network for future job opportunities: "I've gotten to meet a lot of people who all have like real jobs that I can then be like, hey I haven't worked, can I, can you help me out . . . which will be nice." Similarly, Grady talked about the desire to play as long as possible as the driving factor behind his decision to pursue further education, but acknowledged his belief that a graduate degree would serve him better for his long-term goals than would additional undergraduate coursework: "I want to play basketball for as long as I can, but after that ... I wanted to do something that was going to help me later on ... just having a master's in general is going to help you later on . . like when I have to get a real job."

These examples indicate that these graduate student-athletes viewed their sport as their job, and in some ways they felt their position as a graduate student-athlete was helping in their transition to life after sport. But in other ways, they felt the time 
required by their sport was interfering with their ability to take full advantage of the opportunities they felt their classmates had. Adam explained: "I feel like most graduates have jobs ... they work outside of school ... [if not an athlete] I think I would designate more time to be social and more time to my career instead of baseball." Kenzie described the difference between herself and her graduate classmates:

All my classmates work all day ... it's a little different for me cause I don't work cause I have to work out instead . . . the very first week, like introduce yourself, where do you work ... I'm like I don't have a job, but I'm a student-athlete so I promise I'm doing something ... all I know is sports plus academic so it's just kind of different because I don't have a job.

Kenzie went on to talk about how it was difficult for her to pursue internships, which she considered to be the typical route to career entry for her profession:

Trying to find a job while being a student-athlete and internship, especially in an internship-heavy career field, has been really tough, because they'll want you to work tax season . . . but I can't because I'm in season . . . so I'd have to work [my internship] at 5am [or] 10pm, and nobody works then.

She explained that in lieu of the typical internship route, she intended to rely on her experience as a student-athlete to help her stand out among job applicants:

Being an athlete does hold some weight like resume-wise, that sort of thing. A lot of employers understand like this is how I get through school and that I am busy ... I think that if I can market myself as being an athlete . . . that will help me through the fact that I didn't have a job or internship throughout college.

Erin also talked about not being able to take advantage of all the opportunities available to her due to the time demands of her athletics:

I envy people who can just focus on school because they are able to, um they have more opportunity and more time to network [at] any events that are being held ... I always get emails from my teachers about, oh there's this going on and you can come network with us, and listen to so-and-so speak. Those are things I'm not able to partake in.

Like Kenzie, Erin reconciled this perceived disadvantage by using the athletic experience as a training ground for her future. She alluded to this strategy when she explained:

When you're a student-athlete in the graduate program ... not everyone is doing this ... I think you're then ... a little more mature ... [it is known that] this next step is you jumping into the real world . . . I've learned so much just this year, 
being on this program ... about people skills, social skills ... on and off the course ... it was like a job for us ... I think that your resume automatically goes to the top but I think you have to keep it up there, it doesn't stay there because you're a student-athlete ... it's on you what you've learned, so they have to see [what] did you take away from all these years you were a student-athlete.

These students' experiences and words revealed some of the strategies they were utilizing to prepare for their transition away from sport and school.

\section{Discussion}

This study investigated how graduate student-athletes negotiate identity and transition. Using role strain theory and transition theory as theoretical lenses provided perspective on the graduate student-athlete identity negotiation process, and shaped how we made meaning of the findings. Three key themes emerged: (a) life revolves around sport, (b) graduate student-athlete role conflicts, and (c) preparation for life after sport.

Participants in this study possessed a strong sense of athletic identity, especially when they initially entered their graduate degree programs. Their athletic identity was evidenced in their day-to-day time commitment to their sport and the way in which they described prioritizing sport over opportunities such as networking that were provided to them as graduate students. Perhaps the most obvious display of strong athletic identity was participants' choice to pursue graduate study in the first place, tempered by consideration of their athletic demands as a major factor in their choice of program of study (It should also be noted that several participants talked about how their athletic advisors influenced their choice of graduate program of study). From a role theory perspective, it is plausible that these student-athletes felt the pull of their athletic identity role demands with such gravitas that the result was that they felt compelled to make future shaping decisions (e.g., graduate program selection) that were compatible with their athletic identity. From a transition theory perspective, this phenomenon may be evidence of graduate student-athlete transition embracing strategies, or the utilization of available support. However, athletic advisors are not necessarily equipped with training for career counseling. In her study of undergraduate student-athletes, Navarro (2015) warned that, without proper training, athletic student support staff may inadvertently promote academic clustering, in which student-athletes are grouped in the same majors. While this can be problematic at the undergraduate level, graduate programs provide more specialized training that is often intended for specific associated careers. Thus, relying on an athletic advisor for advice on selection of a graduate program may have long-term negative consequences for students as they prepare to transition out of sport and into a career.

The finding that graduate student-athletes select graduate programs based on their athletic demands, as opposed to opting for the most applicable program for their future career interests, and that sometimes this choice is influenced by athletic advisors, demonstrates one way in which graduate student-athletes are different 
from other graduate student populations. Thus, the need is evident to better support graduate student-athletes' decision-making for success in the long term, not just for the duration of their athletic eligibility. Moreover, several participants noted the differences between their undergraduate and graduate studies. Overall, they pointed to several ways in which their graduate experience was different from their undergraduate experience (e.g., more group work, seminar style classes, expectation for autonomy and self-directed learning). In a study on graduate student sense of belonging, Pascale (2018) found some fundamental differences between graduate and undergraduate student experience that contribute to graduate students understanding and operationalizing their sense of belonging differently than they did as undergraduate students. For example, regarding the role of friendships, Pascale's participants noted that undergraduate student's friendships tended to have more of a social focus, whereas graduate friendships revolved around shared academic interests. This study confirms and extends Pascale's findings to graduate student-athlete identity. That is, while athletic identity exists for graduate student-athletes, it appears to be operationally different from undergraduate athletic identity.

Indeed, much of the literature on student-athletes and athletic identity examines undergraduate populations. This literature largely suggests that students who possess strong athletic identity may have a difficult time transitioning out of sport, particularly if they do not have a defined plan for post-baccalaureate life (Melendez, 2006; Mihovilovic, 1968). However, as participants in this study progressed in their graduate programs, many highlighted the ways their program was helping them to prepare for life after sport. In analyzing these graduate student-athletes' words, it became apparent that, whether intentionally or not, participants were utilizing their graduate program of study as a transition strategy, a means to prepare them for what several participants termed the "real world". While they may have entered their graduate programs with a strong athletic identity, they recognized and embraced being "held to a different standard" in their sport, among their teammates, and also in the classroom. Acknowledging the differences between themselves and their teammates may have allowed space for them to dissociate from the notion that their contributions were only athletic, and thus more successfully prepare for transition away from sport. Previous research corroborates these ideas: for example, Melendez (2006) suggested that it is important that student-athletes form a balanced identity to aid in successful transition out of sport.

It has been suggested that graduate student status allows student-athletes added space to fully explore their academic pursuits (Haslerig \& Navarro, 2016). Connecting these ideas with those presented in this study, we postulate that the space provided to more fully explore academic pursuits in graduate school allows for the development of a more balanced identity, which in turn aids in successful transition out of sport. From this perspective, we conclude that pursuit of graduate study may serve as a catalyst for transition, and that perhaps not intentionally, but rather more organically, student-athletes' graduate school experience becomes part of their strategy for transition. 
Some limitations of this study should be noted. First, only six athletes participated, and although they were enrolled at two different institutions, the institutions are similar in size and mission. Thus, because institutional contexts likely influence the experiences of the participants, and to some extent shape their identity and transition, graduate student-athletes enrolled in institutions different from the two in this study may have different experiences. Second, our study includes graduate student-athletes in several different sports, and it is likely that factors including the level of support provided to that sport by the university, whether or not the sport is revenue-producing, and background demographics such as gender and race affect the student-athlete experience. These differences are not addressed in this study, but should be investigated in future research.

\section{Implications and Recommendations}

Findings from this study have important implications for practice and policy. From the reflections provided through these student-athletes' experiences, graduate school can offer an important space for natural transition out of sport and school. However, many of the students indicated that they were not able to take advantage of opportunities that could have expedited the identity-balancing process. We recommend that athletic and academic administrators and coaches work together to create opportunities for graduate student-athletes to substitute for experiences that they may not be able to participate in as a result of their time commitment to their sport. Such experiences could take the form of introductions and scheduled networking time with professionals in their field of study, or pre-arranged one-on-one or small group time with professors to promote mentorship relationships. For students who select sport administration or a related master's program, graduate assistantships could be an effective way for graduate students to take on increased responsibilities and broader roles, which could facilitate a shift in identity and smooth transition to the career side of sport. Additionally, findings from this study could be used by academic advisors, coaches, and recruiters to begin to work more closely with graduate program faculty to successfully recruit and support graduate student-athletes who show potential for a successful transition away from sport and school.

\section{Conclusion}

This study examines identity negotiation and transition of graduate student-athletes. Three themes surfaced: (a) life revolves around sport, (b) graduate student-athlete role conflicts, and (c) preparation for life after sport. Analysis of these themes revealed that the graduate student-athlete participants in this study used their status as graduate students as a part of a strategy for transition, whereby they began to adopt new roles and routines in preparation for their lives after sport. University administrators, coaches, and faculty should encourage graduate study for student-athletes and continue to seek ways to support graduate student-athletes in their identity transition process. 


\section{References}

Adler, P., \& Adler, P. A. (1987). Role conflict and identity salience: College athletics and the academic role. The Social Science Journal, 24(4), 443-455. doi:10.1016/0362-3319(87)90059-0

Adler, P. A., \& Adler, P. (1991). Backboards and blackboards: College athletics and role engulfment. New York, NY: Columbia University Press.

Bacon, V. L., \& Russell, P. J. (2004). Addiction and the college athlete: The Multiple Addictive Behaviors Questionnaire (MABQ) with college athletes. The Sport Journal, 7(2). Retrieved from https://thesportjournal.org/article/addiction-and-the-college-athlete-the-multiple-addictive-behaviors-questionnaire-mabq-with-college-athletes/

Bailey, S., \& Bhattacharyya, M. (2017). A comparison of academic and athletic performance in the NCAA. College Student Journal, 51(2), 173-182.

Blinde, E. M., \& Stratta, T. M. (1992). The" sport career death" of college athletes: Involuntary and unanticipated sport exits. Journal of Sport Behavior, 15(1), 3-20.

Brewer, B. W., Van Raalte, J. L., \& Linder, D. E. (1993). Athletic identity: Hercules' muscles or Achilles heel? International Journal of Sport Psychology, 24(2), 237-254.

Chen, S., Snyder, S., \& Magner, M. (2010). The effects of sport participation on student-athletes' and non-athlete students' social life and identity. Journal of Issues in Intercollegiate Athletics, 3, 176-193.

Coakley, J. J. (1983). Leaving competitive sport: Retirement or rebirth? Quest, 35(1), 1-11. https://doi.org/10.1080/00336297.1983.10483777

Creswell, J. W., \& Poth, C. N. (2018). Qualitative inquiry and research design: Choosing among five approaches (4th ed). Thousand Oaks, CA: Sage.

Fields, S., Collins, C. L., \& Comstock, R. D. (2007). Conflict on the court: A review of sport related violence literature. Trauma, Violence \& Abuse, 8(4), 359-369. doi: $10.1177 / 1524838007307293$

Flyvbjerg, B. (2011). Case study. In N. K. Denzin \& Y. S. Lincoln (Eds.), The SAGE handbook of qualitative research, $4^{\text {th }}$ edition (pp. 301-316). Los Angeles, CA: Sage.

Fountain, J. J., \& Finley, P. S. (2011). Academic clustering: A longitudinal analysis of a Division I football program. Journal of Issues in Intercollegiate Athletics, 4, 24-41.

Foster, S.J., \& Huml, M. R. (2017). The relationship between athletic identity and academic major chosen by student-athletes. International Journal of Exercise Science, 10(6), 915-926.

Galante, M., \& Ward, R. M. (2017). Female student leaders: An examination of transformational leadership, athletics, and self-esteem. Personality and Individual Differences, 106, 157-162.

Glaser, B., \& Strauss, A. (1967). The discovery of grounded theory: Strategies for qualitative research. Mill Valley, CA: Sociology Press. 
Goode, W. J. (1960). A theory of role strain. American Sociological Review, 25, 483496. doi:10.2307/2092933

Gustafsson, H., Martinent, G., Isoard-Gautheur, S., Hassmén, P., \& Guillet-Descas, E. (2018). Performance based self-esteem and athlete-identity in athlete burnout: A person-centered approach. Psychology of Sport and Exercise, 38, 56-60. doi: 10.1016/j.psychsport.2018.05.017

Hale, B. D., \& Waalkes, D. (1994). Athletic identity, gender, self-esteem, academic importance, and drug use: A further validation of the AIMS. North American Society for the Psychology of Sport and Physical Activity Annual Conference. Clearwater Beach, FL.

Harrison, C. K., Stone, J., Shapiro, J., Yee, S., Boyd, J., \& Rullan, V. (2009). The role of gender identities and stereotype salience with the academic performance of male and female college athletes. Journal of Sport \& Social Issues, 33(1), 78-96. doi:10.1177/0193723508328902

Haslerig, S. J. (2017). Graduate(d) student-athletes in Division I football: Redefining archetypes and disrupting stereotypes or invisible? Sociology of Sport Journal, 34(4), 329-343. doi:10.1123/ssj.2017-0003

Haslerig, S. J., \& Navarro, K. M. (2016). Aligning athletes' career choices and graduate degree pathways: Implications for 21st-century career development professionals. Journal of Career Development, 43(3), 211-226. doi: $10.1177 / 0894845315597472$

Jolly, C. J. (2008). Raising the question \# 9: Is the student-athlete population unique? And why should we care? Communication Education, 57(1), 145-151. doi: $10.1080 / 03634520701613676$

Lally, P. S. (2007). Identity and athletic retirement: A prospective study. Psychology of Sport and Exercise, 8(1), 85-99. doi:10.1016/j.psychsport.2006.03.003

Lally, P. S., \& Kerr, G. A. (2005). The career planning, athletic identity, and student role identity of intercollegiate student-athletes. Research Quarterly for Exercise and Sport, 76(3), 275-285. doi:10.1080/02701367.2005.10599299

Lu, L. D., Heinze, K. L., \& Soderstrom, S. (2018) Playing multiple positions: Student-athlete identity salience and conflict. Journal of Intercollegiate Sport, 11(2), 214-241. doi:10.2190/8GLY-G974-V7FM-E1YD

Marcia, J. (1993). The ego identity status approach to ego identity. In J. E. Marcia, A. Waterman, D. R. Matteson, S. L. Archer, \& J. L. Orlofsky (Eds.), Ego identity: A Handbook for Psychosocial Research (pp. 3-21). New York: Springer-Verlag.

Martin, W. C. (2008). The graduate transfer rule: Is the NCAA unnecessarily hindering student-athletes from traversing the educational paths they desire? Villanova Sports \& Entertainment Law Journal, 15, 103-133.

Melendez, M. C. (2006). The influence of athletic participation on the college adjustment of freshmen and sophomore student athletes. Journal of College Student Retention: Research, Theory \& Practice, 8(1), 39-55. doi:10.2190/8GLY-G974V7FM-E1YD

Merriam, S. B. (2009). Qualitative research: A guide to design and implementation. San Francisco, CA: Jossey-Bass. 
Mihovilovic, N. (1968). The status of former sportsmen. International Review of Sport Sociology, 3, 73-96. doi:10.1177/101269026800300105

Miller, P. S., \& Kerr, G. A. (2003). The role experimentation of intercollegiate student athletes. The Sport Psychologist, 17(2), 196-219.

National Collegiate Athletic Association (NCAA). (2015, October 22). Academic attainment of Division I student-athletes who compete as postgraduates [PDF file]. Retrieved from https:/www.ncaa.org/sites/default/files/Postgrad_outcomes_Oct_22_2015_FINAL_web.pdf

National Collegiate Athletic Association (NCAA). (n.d.). Division I academic progress rate (APR). Retrieved from http:/www.ncaa.org/about/resources/research/ division-i-academic-progress-rate-apr

Navarro, K. M. (2015). An examination of the alignment of student-athletes' undergraduate major choices and career field aspirations in life after sports. Journal of College Student Development, 56(4), 364-379. doi:10.1353/csd.2015.0034

Ogilvie, B. C., \& Howe, M. (1982). Career crisis in sport. In Proceedings of the 5th world congress of sport psychology (pp. 176-183). Ottawa: Coaching Association of Canada.

Pascale, A.B. (2018). Co-existing lives: Understanding the role of sense of belonging for graduate student populations. Journal of Student Affairs Research and Practice, 55(4), 399-411. doi:10.1080/19496591.2018.1474758

Pascarella, E. T., Truckenmiller, R., Nora, A., Terenzini, P. T., Edison, M., \& Hagedorn, L. S. (1999). Cognitive impacts of intercollegiate athletic participation: Some further evidence. The Journal of Higher Education, 70(1), 1-26. doi: $10.2307 / 2649116$

Patton, M. (2002). Qualitative research \& evaluation methods (3rd Ed.). Thousand Oaks, CA: Sage.

Sailes, G. A. (1993). An investigation of campus stereotypes: The myth of black athletic superiority and the dumb jock stereotype. Sociology of Sport Journal, 10(1), 88-97. doi:10.1123/ssj.10.1.88

Schlossberg, N. K., Waters, E. B., \& Goodman, J. (1995). Counseling adults in transition: Linking practice with theory (2nd ed.). New York, NY: Springer.

Schneider, R. G., Ross, S. R., \& Fisher, M. (2010). Academic clustering and major selection of intercollegiate student-athletes. College Student Journal, 44(1), 6470.

Settles, I. H., Sellers, R. M., \& Damas, A. (2002). One role or two? The function of psychological separation in role conflict. Journal of Applied Psychology, 87, 574-582. doi:10.1037/0021-9010.87.3.574

Sinclair, D. A., \& Orlick, T. (1993). Positive transitions from high-performance sport. The Sport Psychologist, 7(2), 138-150. doi:10.1123/tsp.7.2.138

Snyder, E. E. (1985). A theoretical analysis of academic and athletic roles. Sociology of Sport Journal, 2, 164-171. doi:10.1123/ssj.2.3.210

Sturm, J.E., Feltz, D.L., \& Gilson, T.A. (2011). A comparison of athlete and student identity for Division I and Division III athletes. Journal of Sport Behavior, 34(3), 295-306. 
Svoboda, B., \& Vanek, M. (1982). Retirement from high level competition. In Proceedings of the 5th world congress of sport psychology (pp. 166-175). Ottawa, ON: Coaching Association of Canada.

Wendling, E., Kellison, T. B., \& Sagas, M. (2018). A conceptual examination of college athletes' role conflict through the lens of conservation of resources theory. Quest, 70(1), 28-47. doi:10.1080/00336297.2017.1333437

Yopyk, D. J. A., \& Prentice, D. A. (2005). Am I an athlete or a student? Identity salience and stereotype threat in student-athletes. Basic and Applied Social Psychology, 27(4), 329-336. doi:10.1207/s15324834basp2704_5

Yukhymenko-Lescroart, M. A. (2018). On identity and sport conduct of student-athletes: Considering athletic and academic contexts. Psychology of Sport and Exercise, 34, 10-19. doi:10.1016/j.psychsport.2017.09.006 